lic systems and certain oxide-metal interfaces, and the crucial role that coadsorbed "promoters" play (such as potassium, alumina, and sulfur) as either structure or bonding modifiers. Adsorbate-induced restructuring of catalysis surfaces, occurring on different time scales (adsorption, catalytic turnover, or longer times), has been suggested as an important event that controls catalytic site activity.

This work has led to the exciting possibility of utilizing the molecular ingredients of catalysis to design new catalysts with tailored activity and selectivity. The Somorjai group has shown that complex, multicomponent catalysts can be constructed using single-crystal surfaces with the proper surface structure as substrates.
Somorjai serves on the editorial boards of 12 journals, has published over $700 \mathrm{sci}-$ entific papers, and has written four books-Introduction to Surface Chemistry and Catalysis (1994), Chemistry in Two Dimensions: Surfaces (1981), Monolayers on Solid Surfaces (1979), and Principles of Surface Chemistry (1972). He has been awarded honorary degrees by universities in Brussels, Paris, and Budapest, and among many other awards and honors, he is a member of the National Academy of Sciences and the American Academy of Arts and Sciences, an honorary member of the Hungarian Academy of Sciences, and a fellow of the American Association for the Advancement of Science and the American Physical Society.
Born in Budapest, Hungary, Somorjai was a fourth-year student in chemical engineering at the Technical University in Budapest when the Hungarian revolution broke out in 1956. He moved to the United States, and in 1960 received a $\mathrm{PhD}$ degree in chemistry from UC-Berkeley. He was on the research staff at IBM in Yorktown Heights, New York for the first four years of his career, and in 1964 joined the Department of Chemistry at Berkeley, becoming a full professor in 1972 .

Somorjai will present his talk, "From Surface Materials to Surface Technologies," at the Awards Ceremony of the MRS Meeting in Boston, Massachusetts, on Wednesday, December 3 at 6:00 p.m. in Salon E, Marriott Hotel.

\title{
Merton C. Flemings Selected for 1997 David Turnbull Lectureship for Contributions to Solidification Processing
}

Merton C. Flemings, Toyota Professor of Materials Processing at the Massachusetts Institute of Technology, has been selected as the 1997 recipient of the David Turnbull Lectureship. He was cited for "his contributions to the foundations and technology of solidification processing and for educating a generation of materials engineers." The David Turnbull Lectureship recognizes the career of a scientist who has made outstanding contributions to understanding materials phenomena and properties through research, writing, and lecturing, as exemplified by David Turnbull.

Flemings's research over the last 40 years has spanned both the basic and applied science of solidification processing, and has had broad impact on solidification theory and experiments, as well as on industrial practices. Even today, his 1974 text, Solidification Processing, is a widely used teaching and reference book for students and practitioners. The paper he and his students published in the early 1960s on microsegregation later became the most extensively referenced paper in the Science Citation Index. He later broadened this work to quantitative analysis of macrosegregation, which radically altered the thencurrent understanding of the topic. His theoretical analyses are now widely used for prediction and control of macrosegregation in continuous casting.

Flemings showed that eutectic-like structures could be obtained in two-phase alloys far from eutectic composition, and he established the basic principles for directional solidification of these in situ composites. He and his students discovered and quantified the basic mechanism of establishing dendrite arm spacings and casting in ingots ("coarsening"), and later

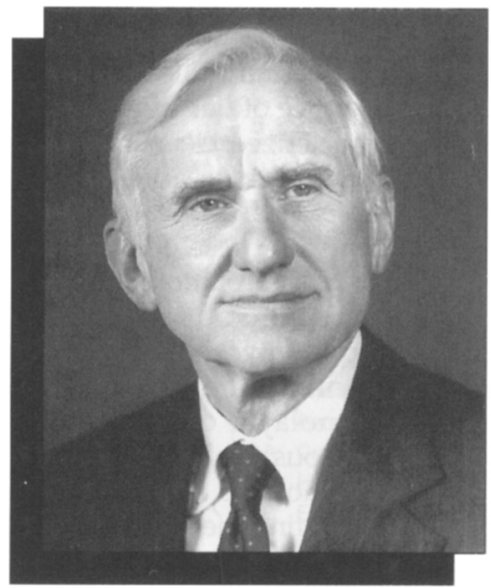

Merton C. Flemings

showed that dendritic structures could be fully eliminated by vigorous agitation during solidification. An industry for forming "semi-solids" developed from this work. He was also the first to show that a dc magnetic field acts as an effective "brake" on fluid flow in solidification processing of metals.

He described mathematically and defined experimentally the fundamentals of flow and solidification behavior in metal matrix composites. His work on the solidification mechanism YBCO superconductors now forms the foundation for, and describes the limits of, practical directional solidification processes for these materials.

This research has led to numerous practical applications, including "premium quality" aluminum castings, "foam vaporization" casting of automotive engine components, braking of fluid flow in con tinuous casting by application of a de magnetic field, semi-solid casting, and reactive melting of intermetallic alloys. Both the foam vaporization process and semi-solid forming process are now used to produce millions of automotive parts each year.

Flemings became head of the Department of Materials Science and Engineering at the Massachusetts Institute of Technology (MIT) in 1982, a position he held until 1995. During this period, he broadened what was effectively a metallurgy department with a small ceramics program to a department with strength across all classes of materials.

After receiving his $\mathrm{ScD}$ degree from $\mathrm{MIT}$ in 1954, Flemings worked in private industry for two years before joining the MIT faculty. He co-chaired the National Materials Study for the National Academy of Sciences in the late 1980s, and served as a co-editor of the recently published Encyclopedia of Advanced Materials. He is the author or co-author of close to 300 papers, holds 26 patents, and has been honored by the Minerals, Metals \& Materials Society, ASM International, AIME, and industry and professional groups in France, Italy, and Japan. Flemings has been named the 1997 recipient of the Acta Metallurgica J. Herbert Hollomon Award. He is a member of the National Academy of Engineering and the American Academy of Arts and Sciences. He recently completed a term as a councillor of MRS.

Flemings will deliver the Turnbull Lecture, "Solidification Science and Engineering Practice," for Symposium B of the MRS Meeting in Boston, Massachusetts, on Mnnday, December 1, at 10:00 a m. in Amencan South, Westin Hutel. 